TECHNO: JURNAL PENELITIAN

Jurnal homepage: http://ejournal.unkhair.ac.id/index.php/Techno

Volume 06 Nomor 02 Oktober 2017

\title{
Studi Karakteristik Agregat Pasir Pantai Mangoli, Sosowomo dan Loto dalam Komposisi Beton
}

\author{
Arbain Tata *1, Irnawaty ${ }^{2}$, Cavaruddin ${ }^{3}$ \\ ${ }^{1}$ Program Studi Teknik Sipil, Fakultas Teknik Universitas Khairun, Ternate \\ 2,3Mahasiswa Teknik Sipil, Fakultas Teknik Universitas Khairun, Ternate \\ *Corresponding authors: arbatata@yahoo.co.id \\ Manuscript received: 05-06-2017 Revision accepted: 14-08-2017
}

\begin{abstract}
Abstrak
Pasir sebagai agregat halus memegang peranan penting dalam menentukan karakteristik struktur beton yang dihasikan, sebab agregat halus mengisi sebagian besar volume beton. Pasir pantai sebagai salah satu jenis material agregat halus memiiki ketersediaan dalam kuantitas yang besar namun sifat fisik yang dimiliki perlu diteliti lebih lanjut. Penelitian ini bertujuan untuk mempelajari komposisi material pasir semen dari tiga quary pasir pantai yang berbeda dibandingkan dengan pasir gunung. Didapatkan kekuatan optimum serta pengaruh variasi faktor air semen (FAS) terhadap kuat tekan dan modulus elastisitas beton pasir pantai. Benda uji yang dibuat adalah selinder dengan ukuran 150 x $300 \mathrm{~mm}$ dengan variasi faktor air semen (FAS) 0,$4 ; 0,5 ; 0,6$ dan 0,7 . Benda uji selinder diuji pada saat umur 28 hari. Hasil penelitian menunjukan bahwa pengujian kuat tekan dari tiga quarry yang berbeda dihasilkan kuat tekan paling tinggi dari pantai Loto. Dari material pasir pantai Loto dilaksanakan pengujian modulus elastisitas dengan nilai FAS divariasikan. Hasil menunjukan terjadi kenaikan nilai kuat tekan dari FAS 0,48 dan 0,4 dari 22,84 MPa menjadi 26,64 MPa, selanjutnya kuat tekan dari FAS 0.5, 0,6 dan 0,7 mengalami penurunan dari 20,32 MPa menjadi 13 FAS 80 MPa dan 11 FAS 73 MPa. Maka variasi optimum yang dapat digunakan adalah variasi FAS 0.4. Begitu pula dengan modulus elastisitas juga mengalami kenaikan dari FAS 0,48 dan 0,4 dari 25063,5 MPa menjadi $26292 \mathrm{MPa}$, selanjutnya variasi FAS dari 0,5; 0,6 dan 0,7 mengalami penurunan dari $23465 \mathrm{MPa}$ menjadi $18906 \mathrm{MPa}$ dan 15133,5 MPa. Maka variasi optimum yang didapat adalah variasi FAS 0,4.
\end{abstract}

Kata kunci: pasir pantai, kuat tekan beton, modulus elastisitas.

\begin{abstract}
Sand as fine aggregate plays important role in determining the characteristics of resulted concrete structure since fine aggregate fills the most part of concrete volume. Beach sand as one of types of fine aggregate material is available in large quantity; however, its physical characteristics need further examination. The research aimed to study the composition of cement sand material and three different beach sand quarries. The optimal strength and the influence of water cement factor (FAS) variation on the pressure strength and modulus elasticity of beach sand concrete were obtained. The test object made was a $150 \times 200 \mathrm{~mm}$ cylinder with variation of water cement factor (FAS) of $0.4 ; 0.5 ; 0.6$ and 0.7. The cylinder was tested on the $28^{\text {th }}$ days. The research result indicates that the test of pressure strength of the three quarries was different. The highest pressure strength was obtained from Loto Beach. Modulus of elasticity testing was conducted on sand material from Loto Beach with varied FAS values. The result indicates that there was an increase in the value of pressure strength of FAS 0.48 and 0.4 from $22.84 \mathrm{MPa}$ to 26.64 MPa. The pressure strength of FAS 0.5, 0.6 and 0.7 experienced a decrease from $20.32 \mathrm{MPa}$ to 13 FAS $80 \mathrm{MPa}$ and 11 FAS $73 \mathrm{MPa}$. Thus, optimum variation that can be used was FAS 0.4 . The modulus of elasticity was also experienced an increase from FAS 0.48 and 0.4 , which was from $25063.5 \mathrm{MPa}$ to $26292 \mathrm{MPa}$. Further, variation of FAS from 0.5; 0.6 and 0.7 experienced a decrease from $23465 \mathrm{MPa}$ to $18906 \mathrm{MPa}$ and $15133.5 \mathrm{MPa}$. Therefore, the optimum variation obtained was variation of FAS 0.4.
\end{abstract}

Keywords: beach sand, pressure strength of concrete, modulus of elasticity. 


\section{PENDAHULUAN}

Berbagai bangunan didirikan menggunakan beton sebagai bahan utama, baik bangunan gedung, bangunan air, maupun bangunan sarana transportasi. Beton tersebut terdiri dari pencampuran antara agregat halus (pasir), agregat kasar (split), dengan menambahkan bahan perekat semen dan air sebagai bahan pembantu guna keperluan reaksi kimia selama proses pengerasan (Mulyono, 2003). Penggunaan beton sebagai konstruksi bangunan tentunya tidak terlepas dari ketersediaan material beton seperti agregat halus, agregat kasar, air dan semen di daerah tersebut. Namun pada kenyataannya, beberapa daerah masih mengalami keterbatasan material pembentuk beton seperti yang terjadi di kecamatan Mangoli barat desa Leko Kadai, dan Kabupaten Halmahera Tengah desa Weda. Di mana keterbatasan material khususnya material pasir disebabkan karena mahalnya harga material akibat jauhnya sumber material tersebut. Hal ini disebabkan karena tidak adanya sumber atau penambang pasir kali di wilayah tersebut.

Pasir laut menjadi pilihan yang banyak digunakan oleh masyarakat di wilayah tersebut sebagai bahan pengganti agregat halus beton. Meski pemakaian pasir laut ini memiliki beberapa kekurangan seperti dapat menyebabkan korosi pada tulangan, namun masyarakat pada umumnya tetap memilih untuk menggunakannya. Selain itu, mutu beton yang dihasilkan dari bahan agregat halus dengan menggunakan pasir laut belum diteliti. Dengan demikian agregat halus dengan menggunakan pasir laut ini belum bisa memberikan jaminan terhadap kualitas beton yang dihasilkan. Pemakaian pasir laut ini dikarenakan sumber material yang cukup dekat, sehingga dapat diperoleh dengan mudah. Karakteristik kualitas agregat halus yang digunakan sebagai komponen struktural beton memegang peranan penting dalam menentukan karakteristik kualitas struktur beton yang dihasikan, sebab agregat halus mengisi sebagian besar volume beton. Pasir laut sebagai salah satu jenis material agregat halus memiiki ketersediaan dalam kuantitas yang besar namun secara kualitas perlu diteliti lebih lanjut terhadap struktur beton.

Penelitian terdahulu mengenai pemenfaatan pasir pantai Semampang dan batu pecah asal Ranai sebagai bahan pembuatan beton normal. Hasil penelitian menunjukan bahwa pasir Semempang mempunyai nilai modulus halus butir 3,07; berat jenis SSD 2,58; berat satuan 1,49, kandungan lumpur $0,44 \%$ kandungan garam 242,77 ppm $(0,024277 \%)$ dan kandungan ion khlorida 147,24 ppm (0,014724\%). Beton dengan FAS 0,4 dengan kandungan semen berturutturut $475 \mathrm{~kg} / \mathrm{m}^{3}$ dan $\quad 550 \mathrm{~kg} / \mathrm{m}^{3}$ diperoleh kuat tekan beton 37,33 MPa dan 36,20 MPa, untuk FAS 0,5 dengan kandungan semen berturut-turut $380 \mathrm{~kg} / \mathrm{m}^{3}$ dan $450 \mathrm{~kg} / \mathrm{m}^{3}$ diperoleh kuat tekan 35,51 MPa dan 31,68 Mpa, sedangkan untuk FAS 0,6 dengan kandungan semen berturut-turut $317 \mathrm{~kg} / \mathrm{m}^{3}$ dan $375 \mathrm{~kg} / \mathrm{m}^{3}$ masing-masing kuat tekan beton adalah 27,69 MPa dan 26,26 MPa. (Stevia, 2009).

Beton adalah suatu material yang terdiri dari campuran semen, air, agregat (kasar dan halus) dan bahan tambah bila diperlukan. Beton yang dipakai pada saat ini yaitu beton normal. Beton adalah beton yang mempunyai berat isi $2200-2500 \mathrm{~kg} / \mathrm{m}^{3}$ dengan menggunakan agregat alam dipecah atau tidak dipecah. Pada umumnya bahan termasuk beton memiliki daerah awal pada diagram tegangan-regangannya dimana bahan berkelakuan secara elastis 
dan linier. Kemiringan diagram tegangan-regangan dalam daerah elastis linier itulah yang dinamakan Modulus Elastisitas (E) atau Modulus Young (Timosenko dan Gere, 1987).

\section{METODE PENELITIAN}

\section{Waktu dan Tempat Penelitian}

Penelitian dilaksanakan di Laboratorium Struktur Dan Bahan Fakultas Teknik Universitas Khairun Ternate, dengan menggunakan metode eksperimental, yaitu pengujian kuat tekan beton pada benda uji silinder yang mengacu pada Standar Nasional Indonesia (SNI).

\section{Bahan dan Peralatan}

Bahan dan peralatan yang digunakan dalam pembuatan benda uji silinder adalah semen Portland tipe-I merek Tonasa, pasir berasal dari pantai Mangoli, Sosowomo dan Loto kerikil dari AMP Tubo Ternate Utara, Air berasal dari PDAM. Benda uji berbentuk selinder dengan diameter $150 \mathrm{~mm}$ dan tinggi $300 \mathrm{~mm}$. dengan agregat pasir pantai dari tiap wilayah dan variasi yang telah direncanakan dapat dilihat pada Tabel 1.

Tabel 1. Komposisi Benda Uji Untuk Agregat Halus Pasir Pantai

\begin{tabular}{cll}
\hline No & \multicolumn{1}{c}{ Kode benda uji } & Jumlah Benda Uji (buah) \\
\hline 1 & Pasir Pantai Sosowomo (PP - SO) & 3 \\
2 & Pasir Pantai Mangoli (PP - MA) & 3 \\
3 & Pasir Pantai Loto (PP - LO) & 3 \\
4 & Pasir Gunung Kalumata (PG - KL) & 3 \\
\hline
\end{tabular}

Peralatan yang digunakan antara lain cetakan silinder ukuran diameter $15 \mathrm{~cm}$ dan tinggi 30 $\mathrm{cm}$, mesin pengujian kuat tekan, mixer beton, meja getar, sekop, timbangan dan alat tambahan lainnya.

\section{Pengujian Bahan}

Untuk mengetahui sifat-sifat fisik agregat halus maka dilakukan pengujian sebagai berikut:
a. Pengujian Kadar Air
b. Pengujian Kadar Lumpur
c. Pengujian analisa saringan agregat halus
d. Pengujian berat jenis dan penyerapan agregat halus
e. Pengujian kadar lumpur agregat halus

Selanjutnya dari hasil pemeriksaan komposisi material pada pasir pantai ditentukan satu quarry untuk dapat diteliti lebih lanjut menyangkut karakteristik campuaran beton berupa kuat tekan dan elastisitas dengan beberapa variasi FAS, dapat dilihat pada Tabel 2. 
Tabel 2. Komposisi benda uji untuk variasi FAS

\begin{tabular}{ccccc}
\hline No & kode & Fas & Jumlah Benda Uji Kuat Tekan (buah) & $\begin{array}{l}\text { Jumlah Benda Uji } \\
\text { Elastisitas (buah) }\end{array}$ \\
\hline 1 & BL & 0.48 & 3 & 2 \\
2 & BVF I & 0,4 & 3 & 2 \\
3 & BVF II & 0,5 & 3 & 2 \\
4 & BVF III & 0,6 & 3 & 2 \\
5 & BVF IV & 0,7 & 3 & 2 \\
\hline
\end{tabular}

\section{Pembuatan Benda Uji}

Rancangan campuran beton pada penelitian ini menggunakan bahan dikajian pustaka. Perawatan benda uji dapat dilakukan dengan perendaman dan juga dapat dengan menutupi beton dengan karung goni basah, namun harus selalu tetap basah. Perawatan benda uji dilakukan untuk menghindari penguapan air pada benda uji.

Adapun cara perendamannya adalah sebagai berikut:

a. Setelah 24 jam dari beton dibuat maka cetakan beton kubus dibuka, lalu dilakukan perendaman terhadap sampel beton tersebut.

b. Perendaman dilakukan sampai umur beton 28 hari didalam air biasa.

c. Sebelum beton direndam terlebih dahulu diberi tanda atau kode penamaan pada permukaan sampel.

\section{HASIL DAN PEMBAHASAN}

\section{Kuat Tekan beton Umur 28 hari}

Hasil pemeriksaan agregat ini dipakai untuk menghitung mix design untuk campuran beton. Beton yang telah dicetak dirawat hingga umur yang telah ditentukan untuk di uji kuat tekan. Untuk mendapatkan beton yang memiliki kuat tekan yang sesuai dengan rencana, diperlukan data-data karakteristik bahan yang akan digunakan untuk campuran beton. Pada Tabel 3, ditunjukkan perbandingan komposisi dari 3 quarry pasir pantai yang bebeda. Seluruh tahap pekerjaan yang direncanakan pada penelitian ini telah selesai dilaksanakan. Berdasarkan hasil penelitian yang dilakukan dilaboratorium maka data yang diperoleh antara lain; pengujian kuat tekan beton dilakukan untuk mendapatkan gambaran mutu beton tersebut. 
Tabel 3. Hasil Pemeriksaan Agregat Halus

\begin{tabular}{|c|c|c|c|c|c|}
\hline \multirow[b]{2}{*}{ No } & \multirow[b]{2}{*}{ Pemeriksaan Pengujian } & \multicolumn{4}{|c|}{ Rata-Rata Hasil Pemeriksaan Agregat Halus } \\
\hline & & $\begin{array}{c}\text { Pasir } \\
\text { Sosowomo }\end{array}$ & $\begin{array}{c}\text { Pasir } \\
\text { Mangol } \\
\text { i }\end{array}$ & $\begin{array}{l}\text { Pasir } \\
\text { Loto }\end{array}$ & Spesifikasi \\
\hline 1 & Kadar Air & 5.00 & 2.50 & 3.50 & $3-5 \%$ \\
\hline 2 & Kadar Lumpur & 3.00 & 3.25 & 1.25 & $0.2-5 \%$ \\
\hline \multirow[t]{3}{*}{3} & Berat Volume & & & & \\
\hline & a. Kondisi Lepas & 1.38 & 1.20 & 1.15 & $1.4-1.9 \mathrm{~kg} / \mathrm{ltr}$ \\
\hline & b. Kondisi Padat & 1.59 & 1.37 & 1.35 & $1.4-1.9 \mathrm{~kg} / \mathrm{ltr}$ \\
\hline 4 & Penyerapan & 4.71 & 1.73 & 1.53 & $0.2-2 \%$ \\
\hline \multirow[t]{4}{*}{5} & Berat Jenis Spesifik & & & & \\
\hline & a. Bj. Kering Oven & 2.53 & 2.59 & 2.66 & $1.6-3.2 \%$ \\
\hline & b. Bj. Kering Permukaan & 2.65 & 2.63 & 2.70 & $1.6-3.2 \%$ \\
\hline & c. Bj. Semu & 2.87 & 2.71 & 2.78 & $1.6-3.2 \%$ \\
\hline 6 & Modulus Kehalusan & 2.25 & 1.78 & 2.81 & $2.2-3.1 \%$ \\
\hline
\end{tabular}

Dari tabel 3 properties agregat umumnya memenuhi spesifikasi kecuali kadar air pada agregat halus dari quarry Sosowomo dan Loto. Modulus kehalusan quarry Mangoli di bawah spesifikasi, ini memperlihatkan bahwa agregat halus tersebut sangat halus.

Tabel 4. Rekapitulasi Hasil Pengujian Kuat Tekan Beton FAS 0,40

\begin{tabular}{ccccc}
\hline No & $\begin{array}{c}\text { Kode } \\
\text { Benda Uji }\end{array}$ & $\begin{array}{c}\text { Umur Perawatan } \\
\text { (hari) }\end{array}$ & $\begin{array}{c}\text { Kuat Tekan } \\
\text { Rata-rata } \\
(\mathrm{MPa})\end{array}$ \\
\hline 1 & PP-LO & 28 & 22,84 \\
2 & PP-MA & 28 & 19,21 \\
3 & PP-SO & 28 & 16,25 \\
4 & PP-KL & 28 & 24,96 \\
\hline
\end{tabular}

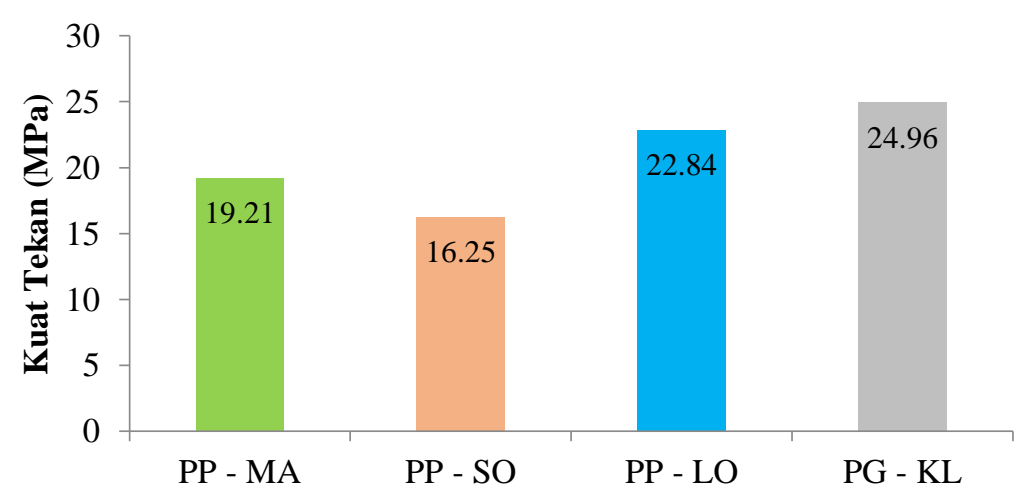

Gambar 1. Kuat Tekan Kuat tekan beton dengan quary berbeda

Dari hasil pengujian kuat tekan beton dengan agregat halus pasir pantai dan pasir gunung nampak ada penurunan kekuatan yanhg signifikan. Pada pasir Gunung Kalumata 
menghasilkan kuat tekan sebesar 24,96 Mpa dengan kuat tekan rencana fc $25 \mathrm{Mpa}$. Dan untuk pasir pantai dari tiga wilayah yang berbeda yaitu pasir pantai Mangoli, Sosowomo dan Loto. Ternyata pasir pantai menghasilkan variasi kekuatan yang cukup signifikan yaitu, pasir Loto menghasilkan kuat tekan sebesar 22,84 Mpa, kuat tekan pasir pantai Mangoli sebesar 19,21 Mpa, pasir pantai Sosowomo sebesar 16,25 Mpa.

Tabel 5. Rekapitulasi Hasil Pengujian Kuat Tekan Beton dengan Variasi FAS

\begin{tabular}{|c|c|c|c|c|}
\hline No & Kode Sampel & Jenis Variasi & $\begin{array}{l}\text { Umur } \\
\text { (hari) }\end{array}$ & $\begin{array}{l}\text { Kuat Tekan rata-rata } \\
(\mathrm{Mpa})\end{array}$ \\
\hline 1 & PPLO - 0,48 & & & 22,84 \\
\hline 2 & $\mathrm{~V} 1-0,40$ & & & 26,64 \\
\hline 3 & $\mathrm{~V} 2-0,50$ & Kadar Air Tetap & 28 & 20.32 \\
\hline 4 & $\mathrm{~V} 3-0,60$ & & & 13,80 \\
\hline 5 & $\mathrm{~V} 4-0,70$ & & & 11.73 \\
\hline
\end{tabular}

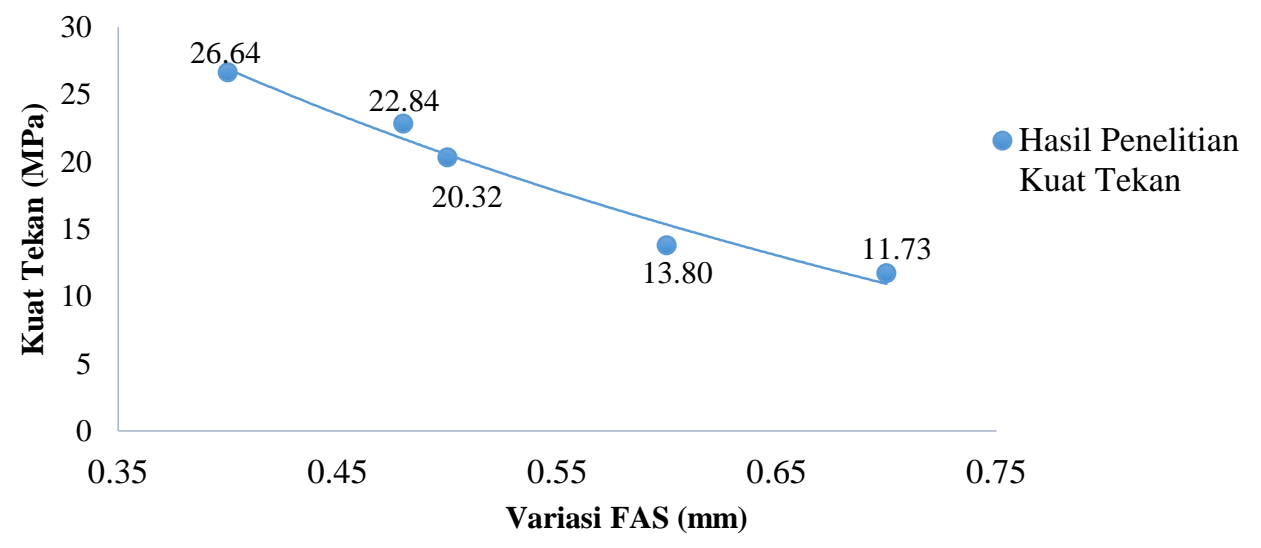

Gambar 2. Hubungan Variasi FAS Terhadap Kuat Tekan Beton pasir loto

Dari gambar 2, hasil pengujian kuat tekan berdasarkan dengan dengan variasi faktor air semen (FAS) 0,70 dengan kuat tekan sebesar 11,73 Mpa, FAS 0,60 kuat tekan yang diperoleh 13,80 Mpa, FAS 0,50 diperoleh kuat tekan sebesar 20,32 Mpa dan FAS 0,40 diperoleh kuat tekan sebesar 26,64 Mpa. Dari hasil pengujian menunjukkan makin kecil nilai FAS maka makin besar kuat tekan beton yang diperoleh, karena semakin tinggi tingkat kepadatannya maka semakin besar kuat tekan beton yang dihasilkan, dan makin besar faktor air semen akan meningkatkan nilai porositas menunjukan bahwa beton memiliki pori yang cukup besar akibat terjadinya penguapan air dan pemuaian material pengisi beton sehingga kuat tekan beton menurun. Analisa data menggunakan Metode Regresi untuk menentukan atau menganalisis data-data yang diperoleh dari hasil penelitian, sehingga hubungan antara sifat karakteristik agregat terhadap kuat tekan beton dapat diketahui. 
Tabel 6. Hubungan Modulus Elastisitas dengan Variasi FAS Terhadap Elastisita Beton pasir loto

\begin{tabular}{|c|c|c|c|c|c|}
\hline $\begin{array}{c}\text { No. } \\
\text { Sampel }\end{array}$ & $\begin{array}{l}\text { Kode sampel } \\
\text { Variasi Faktor Air } \\
\text { Semen (FAS) }\end{array}$ & $\begin{array}{c}\text { Ec } \\
\text { Perhitungan } \\
\mathrm{MPa}\end{array}$ & $\begin{array}{c}\text { Ec Rerata } \\
\text { Mpa }\end{array}$ & EC & $\begin{array}{l}\text { Ec Teoritis ( MPa ) } \\
=\mathbf{0 . 0 4 3} \times \mathbf{W c}^{1} \cdot \sqrt[5]{\mathbf{f c}} \\
\mathbf{E C}=\mathbf{4 7 0 0} \sqrt{\mathbf{f c}}\end{array}$ \\
\hline $\begin{array}{l}01 \\
02\end{array}$ & $\mathrm{BN}-0,48$ & $\begin{array}{l}25690 \\
24437\end{array}$ & 25063.50 & & 23979,50 \\
\hline $\begin{array}{l}01 \\
02\end{array}$ & $\mathrm{~V} 1-0,4$ & $\begin{array}{l}26417 \\
26167\end{array}$ & 26292.00 & & 25001,50 \\
\hline $\begin{array}{l}01 \\
02\end{array}$ & V2 - 0,5 & $\begin{array}{l}23810 \\
23120\end{array}$ & 23465.00 & & 21793,00 \\
\hline $\begin{array}{l}01 \\
02\end{array}$ & V3 - 0,6 & $\begin{array}{l}18906 \\
18906\end{array}$ & 18906.00 & & 17390,38 \\
\hline $\begin{array}{l}01 \\
02\end{array}$ & $\mathrm{~V} 4-0,7$ & $\begin{array}{l}14405 \\
15862\end{array}$ & 15133.50 & & 14882,00 \\
\hline
\end{tabular}

Data yang diambil dari seluruh benda uji dilakukan dengan mesin penguji tekan dan alat pengukur regangan, pengambilan data tegangan dan regangan dicatat pada setiap penambahan beban dengan laju pembebanan yang konstan dan pengujian dilakukan pada benda uji silinder beton umur 28 hari. Kurva tegangan-regangan diperoleh dengan memplotkan data-data tegangan setiap kenaikan beban $40 \mathrm{kN}$. Analisa modulus elastisitas dari masing masing benda uji dapat dilihat pada Tabel 6 .

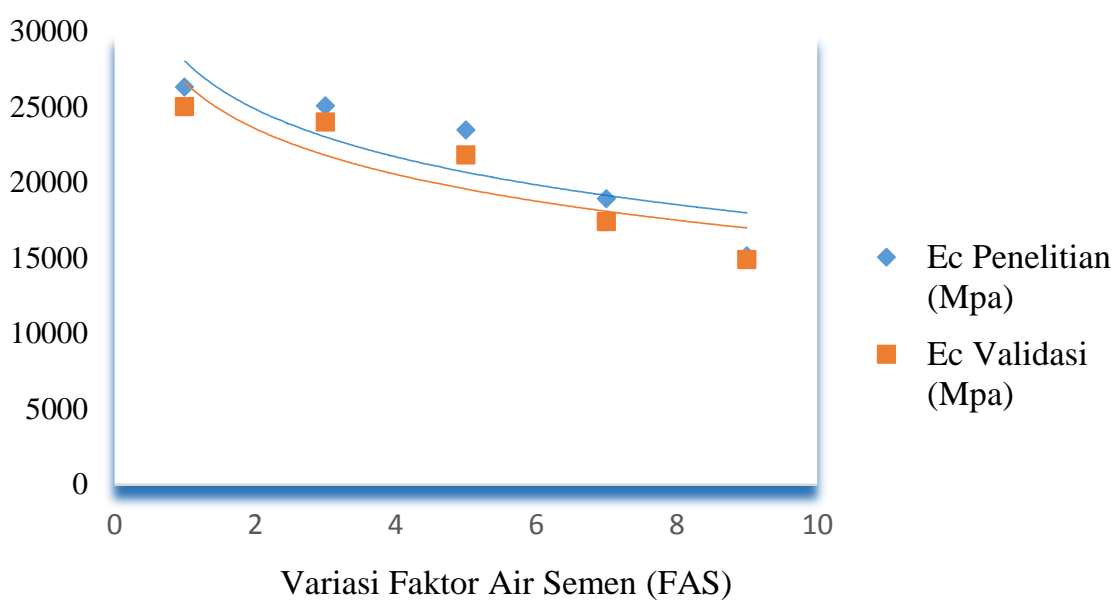

Gambar 3. Grafik perbandingan antara nilai modulus elastisitas hasil penelitian dan analisis pada beton dengan variasi FAS umur 28 hari.

Dari Gambar 3, dapat diketahui pengaruh variasi faktor air semen terhadap nilai modulus elastisitas. Nilai modulus elastisitas meningkat seiring dengan bertambahnya kandungan semen, peningkatan terjadi pada beton dengan FAS 0,4 yaitu sebesar $26292 \mathrm{MPa}$ atau meningkat sebesar $4.90 \%$ dari beton PP - LO dengan FAS 0,48 dengan modulus elastisitas sebesar 25063,5 MPa. Sedangkan pada variasi FAS 0,5, 0,6 dan 0,7 mengalami penurunan sebesar 23465, 18906, dan 15133,5 MPa. 


\section{SIMPULAN}

Beberapa kesimpulan dari hasil yang diperoleh sebagai berikut:

1. Untuk penggunaan pasir pantai sebagai bahan campuran agregat halus dari masingmasing sumber yang berbeda seperti: pasir pantai Mangoli, Sosowomo dan loto. Pasir pantai Loto cukup baik digunakan sebagai bahan campuran agregat halus, karena menghasilkan kuat tekan sebesar 22,84 MPa cukup dekat dengan mutu beton yang direncanakan yaitu fc $25 \mathrm{MPa}$.

2. Dengan variasi faktor air semen (FAS) dapat memberikan kontribusi positif terhadap beton, dimana dengan FAS 0,4 dapat meningkatkan nilai kuat tekan beton sebesar 26,64 $\mathrm{MPa}$, yang berarti terjadi kenaikan sebesar 16,64 \% dibandingkan dengan beton PP-LO (FAS 0,48) dengan kuat tekan 22,84 MPa. Sedangkan pada variasi FAS 0,5 mutu beton mengalami penurunan sebesar 20,32 Mpa sampai pada FAS 0,6 dan 0,7 mengalami penurunan sebesar 13,80 MPa dan 11,73 MPa.

3. Nilai modulus elastisitas meningkat seiring dengan bertambahnya kandungan semen, peningkatan terjadi pada beton dengan FAS 0,4 yaitu sebesar $26292 \mathrm{MPa}$ atau meningkat sebesar $4.90 \%$ dari beton PP - LO dengan FAS 0,48 dengan modulus elastisitas sebesar 25063,5 MPa. Sedangkan pada variasi FAS 0,5, 0,6 dan 0,7 mengalami penurunan sebesar 23465, 18906, dan 15133,5 MPa.

\section{DAFTAR PUSTAKA}

ASTM C330-03. 1996. Standard Specification for Lightweight Aggregates for Structural Concrete, ASTM Standards: Concrete and Aggregates, V.04.02., Philadelphia.

ASTM C567-91. 1996. Test Method for Unit Weight of Structural Lightweight Concrete, ASTM Standards: Concrete and Aggregates, V.04.02., Philadelphia.

ASTM C39-94. 1996. Test Method for Compressive Strength of Cylindrical Concrete Specimens, ASTM Standards: Concrete and Aggregates, V.04.02., Philadelphia.

ASTM C496-96. 1996. Test Method for Splitting Tensile Strength of Cylindrical Concrete Specimens, ASTM Standards: Concrete and Aggregates, V.04.02., Philadelphia

Badan Stndaraisasi Nasional Indonesia. 1990. Metode Pengujian Kuat Tekan Beton (SNI 03 1974 - 1990), Jakarta.

Depertemen Pekerjaan Umum. 1991. Tata Cara Pembuatan Rencana Campuran Beton Normal. SK SNI T - 15 - 1990 - 03, Yayasan LPMB, Bandung.

Ahmad, D., Jurnal, F. 2015. Analisis Penggunaan Pasir Pantai Sampur sebagai Agregat Halus Terhadap Kuat Tekan Beton, Vol. 3 No. 1

Maria M.M. 2013. Pemeriksaan Kuat Tekan Beton dan Modulus Elastisitas Beton Beragregat Kasar Batu Ringan Ape dari Kepulauan Talaud, Jurnal Sipil Statik, Vol 1 No.7

Paul, N., Antoni. 2007. Teknologi Beton. Penerbit ANDI: Yogyakarta

Rosie, A.I.S. .2015. Pengaruh Jumlah Semen dan Fas Terhadap Kuat Tekan Beton dengan Agregat yang Berasal Dari Sungai, Jurnal Sipil Statik, Vol.3 No.1

Tri, M. 2005. Teknologi Beton. Penerbit ANDI: Yogyakarta 